\title{
lodine-Induced Fetal Hypothyroidism: Diagnosis and Treatment with Intra-Amniotic Levothyroxine
}

\author{
Macy T. Hardley ${ }^{a}$ Andrew H. Chon ${ }^{b}$ Jorge Mestman ${ }^{c}$ Caroline T. Nguyen ${ }^{d}$ \\ Mitchell E. Geffner ${ }^{\mathrm{e}}$ Ramen H. Chmait ${ }^{\mathrm{b}}$
}

${ }^{a}$ Keck School of Medicine, University of Southern California, Los Angeles, CA, USA; ${ }^{b}$ Division of Maternal-Fetal Medicine, Department of Obstetrics and Gynecology, Keck School of Medicine, University of Southern California, Los Angeles, CA, USA; ' Division of Endocrinology, Diabetes, and Metabolism, Department of Medicine and Obstetrics and Gynecology, Keck School of Medicine, University of Southern California, Los Angeles, CA, USA; dDivision of Endocrinology, Diabetes, and Metabolism, Department of Medicine, Keck School of Medicine, University of Southern California, Los Angeles, CA, USA; ${ }^{\mathrm{e}}$ The Saban Research Institute, Children's Hospital Los Angeles, Keck School of Medicine, University of Southern California, Los Angeles, CA, USA

\section{Established Facts}

- Excess iodine ingestion by a pregnant woman can cause fetal hypothyroidism and goiter development because of the inability of the fetus to escape the Wolff-Chaikoff effect.

- Infants with congenital hypothyroidism remain at risk for some degree of impaired neurodevelopment even with adequate screening and postnatal treatment.

\section{Novel Insights}

- Serial fetal blood sampling confirmed fetal escape from the Wolff-Chaikoff effect in the mid third trimester.

- Intra-amniotic treatment of fetal hypothyroidism may decrease the risk of impaired neurodevelopment.

\section{Keywords}

Fetal goiter · Fetal hypothyroidism · Intra-amniotic treatment $\cdot$ lodine $\cdot$ Wolff-Chaikoff effect

\footnotetext{
Abstract

Background: lodine is necessary for fetal thyroid development. Excess maternal intake of iodine can cause fetal hypothyroidism due to the inability to escape from the WolffChaikoff effect in utero. Case Report: We report a case of
}

fetal hypothyroid goiter secondary to inadvertent excess maternal iodine ingestion from infertility supplements. The fetus was successfully treated with intra-amniotic levothyroxine injections. Serial fetal blood sampling confirmed fetal escape from the Wolff-Chaikoff effect in the mid third trimester. Early hearing test and neurodevelopmental milestones were normal. Conclusion: Intra-amniotic treatment of fetal hypothyroidism may decrease the rate of impaired neurodevelopment and sensorineural hearing loss.

(C) 2018 S. Karger AG, Base

\section{KARGER}

E-Mail karger@karger.com

www.karger.com/hrp
๑) 2018 S. Karger AG, Basel Ramen H. Chmait, MD

Keck School of Medicine, University of Southern California

39 Congress St, Suite 302

Pasadena, CA 91105 (USA)

E-Mailchmait@usc.edu 


\section{Introduction}

The developing fetus requires iodine for proper thyroid function $[1,2]$. Excess iodine can inhibit proper thyroid function in the fetus, causing hypothyroidism and resulting in a fetal goiter $[3,4]$. Being a relatively rare condition, fetal goiter has several possible etiologies including iodine excess or deficiency, congenital dyshormonogenesis, transplacental passage of maternal thyrotropin receptor antibodies, and excess maternal thionamide dosage. A fetal goiter can be diagnosed by antenatal ultrasound [5]. Intra-amniotic levothyroxine injections have been utilized to treat fetal hypothyroidism and goiter [68]. However, the impact of intrauterine therapy on neurodevelopmental outcome remains controversial [7, 9]. Some evidence suggests that waiting until the postnatal period to administer treatment leaves the infant at risk for impaired neurodevelopment $[1,7,10-12]$.

We present a case of inadvertent maternal ingestion of excess iodine from thyroid supplements provided for infertility treatment resulting in fetal hypothyroidism that was treated with serial intra-amniotic levothyroxine injections, with the goals of preventing respiratory obstruction at birth and reducing the risk of neurodevelopmental impairment. Serial fetal blood sampling documented fetal escape from the Wolff-Chaikoff effect in the mid third trimester. The risks of ingestion of excess iodine during pregnancy are emphasized.

\section{Case Report}

A 39-year-old woman was referred at 21 4/7 weeks' gestation for potential therapy of a fetal goiter. Ultrasound findings at initial consultation were significant for a hypervascular, bilobed, symmetrical fetal goiter that measured $2.0 \mathrm{~cm}$ cranio-caudal $(\mathrm{cc}) \times 2.2$ $\mathrm{cm}$ transverse $(\mathrm{tr}) \times 1.4 \mathrm{~cm}$ antero-posterior (ap). Reference fetal thyroid dimensions (mean $\pm \mathrm{SD}$ ) at this gestational age are $0.73 \pm$ $0.05 \mathrm{~cm}(\mathrm{cc}) \times 1.0 \pm 0.31 \mathrm{~cm}(\mathrm{tr}) \times 0.28 \pm 0.03 \mathrm{~cm}(\mathrm{ap})$ [13]. The trachea was visible, but compressed in the region of the goiter. Polyhydramnios was present.

The mother was euthyroid 3 months prior to pregnancy (thyroid-stimulating hormone $[\mathrm{TSH}]=2.77 \mathrm{mIU} / \mathrm{L}$, free thyroxine $[\mathrm{FT} 4]=1.4 \mathrm{ng} / \mathrm{dL}$, total triiodothyronine $[\mathrm{T} 3]=70 \mathrm{ng} / \mathrm{dL}$, free T3 [FT3 $]=2.5 \mathrm{pg} / \mathrm{mL}$, and negative anti-thyroglobulin and anti-thyroperoxidase antibodies). Maternal urinary iodine levels were not measured. However, as part of a fertility-promoting program, the patient's naturopathic provider recommended that she ingest several fertility-promoting vitamin and dietary supplements, of which two were specifically for maternal thyroid health. The first was 40 mg daily of a thyroid biotic made from porcine glandular concentrate, and the second was $12.5 \mathrm{mg}$ daily of iodine $(7.5 \mathrm{mg}$ of iodine from potassium iodide $+5 \mathrm{mg}$ of free iodine). Both supplements were initiated approximately 12 weeks prior to conception. Recom- mendations for iodine supplementation in pregnancy are as follows: World Health Organization (WHO) - $250 \mu \mathrm{g} /$ day $[14,15]$, American Thyroid Association (ATA) - 220-250 $\mu \mathrm{g} /$ day $[15,16]$, and Institute of Medicine (IOM) - $220 \mu \mathrm{g} /$ day $[15,17]$. Repeat maternal thyroid studies at $41 / 7$ weeks' gestation (TSH $1.76 \mathrm{mIU} / \mathrm{L}$ and FT4 $1.2 \mathrm{ng} / \mathrm{dL}$ ) and at 20 5/7 weeks' gestation (TSH $1.04 \mathrm{mIU} / \mathrm{L}$ and FT4 $1.0 \mathrm{ng} / \mathrm{dL}$ ) both revealed a euthyroid maternal state.

The patient was informed of our suspicion of fetal hypothyroidism goiter due to transplacental transfer of maternal excess ingested iodine, and was advised to immediately discontinue the thyroid biotic and the iodine supplement. After a discussion of the risks and benefits of invasive in utero testing, the patient elected to proceed. An informed consent form approved by the institutional review board of the University of Southern California was signed by the patient. A fetal blood sample to assess fetal thyroid status and a genetic amniocentesis was performed at $214 / 7$ weeks' gestation. Fetal TSH was $94.4 \mathrm{mIU} / \mathrm{L}$ and FT4 $0.5 \mathrm{ng} / \mathrm{dL}$, consistent with severe fetal hypothyroidism $[18,19]$ (Table 1). Amniocentesis revealed a 46,XX karyotype and a normal prenatal microarray.

Management options were discussed, including: (1) serial, prophylactic intra-amniotic levothyroxine injections; (2) expectant management with subsequent intra-amniotic levothyroxine injections if pregnancy-related complications developed, such as esophageal or tracheal compression, or high-output cardiac failure; and (3) termination of pregnancy. The patient was informed about the controversial nature of the impact of intra-amniotic levothyroxine injections on the future neurodevelopmental outcome of the child. Furthermore, the possibility of expectant management after cessation of iodine supplements resulting in normalization of fetal thyroid function and goiter resolution was discussed. The patient elected to proceed with serial intra-amniotic levothyroxine injections (500 $\mu \mathrm{g}$ every 2 weeks). This dose was chosen in order to deliver approximately $10 \mu \mathrm{g} / \mathrm{kg} /$ day to the fetus, assuming $10 \%$ of the medication was swallowed and absorbed $[9,20,21]$. The decision was made to also treat the mother with $100 \mu \mathrm{g}$ of levothyroxine daily due to the concern that abrupt discontinuation of the maternal thyroid supplement may induce maternal hypothyroidism, which would potentially compound the already severe fetal hypothyroidism.

Intra-amniotic levothyroxine injection No. 1 was performed at 22 4/7, No. 2 at 24 0/7, and No. 3 at 26 4/7 weeks' gestation. During this time, the fetal goiter remained stable in size. Immediately following the third injection, a repeat fetal blood sample was performed at $264 / 7$ weeks' gestation and demonstrated fetal euthyroidism [18, 19] (Table 1). At 30 4/7 weeks' gestational age, the fetal goiter had decreased in size, and the tracheal compression and polyhydramnios had resolved. On the same day (30 4/7 weeks' gestation), a third fetal blood sample was performed to verify normal fetal thyroid status after discontinuation of intra-amniotic levothyroxine injections for 4 weeks, and euthyroid status of the fetus was confirmed (Table 1). Beginning at $324 / 7$ weeks, the goiter was no longer visible on ultrasound. Fetal MRI at 33 1/7 weeks' gestation showed mild thyroid enlargement without tracheal narrowing, and no other abnormalities.

The patient delivered at 39 2/7 weeks' gestation by cesarean section, which was indicated due to arrest of descent. The female infant weighed 3,458 g and the thyroid was not palpable at birth. Postnatal thyroid studies revealed a stable euthyroid state by day of life (DOL) 7 (Table 2). Hearing screening of the neonate revealed a normal response bilaterally. At the age of 7 months, the infant was euthyroid, healthy, and meeting all developmental milestones. 
Table 1. Fetal thyroid studies from fetal blood sampling

\begin{tabular}{lccc}
\hline Fetal thyroid function test & $214 / 7$ weeks & $264 / 7$ weeks & $304 / 7$ weeks \\
\hline $\mathrm{TSH}, \mu \mathrm{IU} / \mathrm{L}$ & $94.4(\mathrm{H})$ & 2.496 & 3.449 \\
$\mathrm{~T} 4, \mu \mathrm{g} / \mathrm{dL}$ & $1.4(\mathrm{~L})$ & - & - \\
Free T4, ng/dL & $0.5(\mathrm{~L})$ & 1.2 & 1.3 \\
Free T3, pg/mL & 1.7 & 1.2 & 1.4 \\
Anti-thyroglobulin antibodies, IU/mL & 16 & $<15$ & $<15$ \\
Anti-thyroperoxidase antibodies, IU/mL & 36 & $<28$ & $<28$ \\
\hline
\end{tabular}

For reference ranges, see Thorpe-Beeston et al. [18] and Fisher and Brown [44]. TSH, thyroid-stimulating hormone; T4, thyroxine; T3, triiodothyronine; L, low; H, high.

Table 2. Newborn thyroid status

\begin{tabular}{lllllll}
\hline Neonatal thyroid function test & DOL 1 & DOL 2 & DOL 4 & DOL 7 & DOL 38 & DOL 202 \\
\hline TSH, $\mu \mathrm{IU} / \mathrm{mL}$ & 2.83 & 1.70 & $0.62(\mathrm{~L})$ & 1.53 & 1.86 & 2.3 \\
Free T4, ng/dL & 3.73 & 4.53 & 3.59 & 3.31 & 1.16 & 1.12 \\
T3, ng/mL & 2.08 & - & - & - & - & - \\
Free T3, pg/mL & $8.3(\mathrm{H})$ & $10.8(\mathrm{H})$ & 5.3 & 6.4 & 4.2 & - \\
\hline
\end{tabular}

For reference ranges, see Lahoti and Frank [45], Abuid et al. [46], and Erenberg et al. [47]. DOL, day of life; TSH, thyroid-stimulating hormone; T4, thyroxine; T3, triiodothyronine; L, low; H, high.

\section{Discussion}

This case highlights the fetal risks of excess maternal ingestion of iodine and describes the controversial management approach of serial intra-amniotic levothyroxine injections. The ingestion of over 50 times the recommended dose of iodine until $214 / 7$ weeks' gestation by our patient resulted in severe fetal hypothyroidism and fetal goiter. This case also documented fetal escape from the Wolff-Chaikoff effect in the mid third trimester.

Furthermore, serial postnatal studies demonstrated a long-term euthyroid state. Of note, the DOL 1 ( $15 \mathrm{~h}$ after birth) and DOL 2 (40 h after birth) TSH measurements were not elevated, as normally would be expected from the physiologic TSH surge that occurs immediately after birth. Since the TSH levels exponentially fall within the second hour of life [22, 23], the DOL 1 measurement may have occurred after the postnatal peak TSH with levels having already dropped down into the normal range. The free T4 level in the upper end of the normal range and the elevated free $\mathrm{T} 3$ level also provide indirect evidence that a TSH surge did occur.

Fetal Hypothyroidism: In utero Diagnosis and Treatment
The fetus is considered especially vulnerable to the suppressive effects of excess iodine because of the inability of the fetus to escape from the Wolff-Chaikoff effect [24], which is a protective mechanism that prevents excess thyroid hormone production if plasma levels of iodine suddenly increase $[25,26]$. Although not entirely understood, the Wolff-Chaikoff effect is partially explained by a decrease in thyroid peroxidase activity in the setting of excess iodine $[3,27]$ resulting in transient blockage of thyroid hormone synthesis and transient hypothyroidism $[25,28]$. In the mature postnatal thyroid, normal thyroid function resumes after several days due to downregulation of the $\mathrm{Na}^{+} / \mathrm{I}^{-}$symporter (NIS) [24]. The decrease in NIS activity and subsequent decrease in intracellular iodide concentration enables the synthesis of thyroid hormone to resume. However, the precise time in which escape from the Wolff-Chaikoff effect develops in the human fetus is unknown. Studies in rats have shown that the ability to escape thyroid gland suppression develops around 18 days of postnatal life $[29,30]$. Because the midgestation fetus may not be able to escape the Wolff-Chaikoff effect, excess iodine can result in persistent fetal hy-

Horm Res Paediatr 2018;90:419-423 
pothyroidism [31]. In our case, the normalization of the fetal TSH had occurred by the time of the second fetal blood sample during the 26th week of gestation. To determine if the normalization was only transient as a result of serial intra-amniotic levothyroxine injections, a third fetal blood sample was obtained 4 weeks after the last intra-amniotic levothyroxine dose and confirmed evidence of fetal escape from the Wolff-Chaikoff effect during the 30 th gestational week. Thus, we hypothesize that, within the interval of stopping the iodine supplement at the gestational age of 21 weeks and the final fetal blood sample at 30 weeks, there was downregulation of the fetal NIS allowing for resumption of thyroid hormone synthesis. A more precise estimation of when fetal thyroid hormone production returned is not possible given the concurrent intra-amniotic levothyroxine injections until 26 weeks and that fetal concentrations of iodine were not (serially) measured.

Fetal hypothyroidism may be detected clinically via ultrasound due to the presence of a fetal goiter. Potential pregnancy- and delivery-related complications associated with the fetal goiter are multiple. Esophageal compression leads to the decreased ability of the fetus to swallow amniotic fluid, resulting in polyhydramnios, which increases the risk for preterm delivery $[32,33]$. Tracheal compression can lead to asphyxia after birth [32, 33]. Intrathyroidal arteriovenous shunting can cause high-output cardiac failure of the fetus and secondary hydrops [34]. In addition, neck hyperextension from the goiter preventing fetal head flexion could result in malpresentation during delivery and delivery dystocia $[35,36]$.

The impact of intra-amniotic levothyroxine treatment on neurodevelopmental outcome remains unknown. It has previously been thought that the fetal brain is unaffected by lack of fetal thyroid hormones, in large part due to transplacental transport of thyroxine from the mother, such that postnatal thyroid hormone replacement should be sufficient for normal neurodevelopment [37]. However, recent studies have shown that, even with adequate screening and postnatal treatment, infants with congenital hypothyroidism may be at risk for some degree of impaired neurodevelopment $[1,7,10-12]$. This may partly be due to the lack of adequate thyroid hormone levels early in the first trimester, as the fetal thyroid does not produce hormones until approximately 10 weeks' gestation [38]. The precise degree of maternal contribution to fetal thyroid hormone levels up to mid-gestation is not clearly understood [39]. The fetal blood sample in our case at 21 weeks' gestation showed a low T4 concentration, despite a maternal euthyroid state the week prior. Thus, the T4 level in a fetus even at mid-gestation may still largely originate from the fetal thyroid gland with minimal contribution from transplacental passage.

Our patient is similar to one recently presented in a case report by Overcash et al. [40] in which the mother was also taking 50 times the dose of iodine recommended in pregnancy, resulting in a fetal goiter, with discontinuation of the supplements at 29 weeks' gestation. However, in that case, the patient was not treated with intra-amniotic levothyroxine injections. That infant was later diagnosed with bilateral hearing loss, which is a known complication of fetal hypothyroidism [41-43]. Hearing screening in our case revealed a normal response bilaterally. Further studies need to be done to determine if intra-amniotic treatment of hypothyroid fetuses significantly decreases the rate of postnatal sensorineural hearing loss.

\section{Statement of Ethics}

This manuscript complied with all patient protection criteria stipulated by the institutional review board of the University of Southern California.

\section{Disclosure Statement}

The authors report no conflict of interest.

\section{References}

1 Glorieux J, Dussault J, Van Vliet G. Intellectual development at age 12 years of children with congenital hypothyroidism diagnosed by neonatal screening. J Pediatr. 1992 Oct; 121(4):581-4

2 Zhou SJ, Anderson AJ, Gibson RA, Makrides M. Effect of iodine supplementation in pregnancy on child development and other clinical outcomes: a systematic review of randomized controlled trials. Am J Clin Nutr. 2013 Nov;98(5):1241-54.
3 Leung AM, Braverman LE. Consequences of excess iodine. Nat Rev Endocrinol. 2014 Mar; 10(3):136-42.

4 Thomas JV, Collett-Solberg PF. Perinatal goiter with increased iodine uptake and hypothyroidism due to excess maternal iodine ingestion. Horm Res. 2009;72(6):344-7.

5 Perry RJ, Hollman AS, Wood AM, Donaldson MD. Ultrasound of the thyroid gland in the newborn: normative data. Arch Dis Child Fetal Neonatal Ed. 2002 Nov;87(3):F209-11. 
6 Mirsaeid Ghazi AA, Ordookhani A, Pourafkari M, Fallahian M, Bahar A, Hedayati $\mathrm{M}$ et al. Intrauterine diagnosis and management of fetal goitrous hypothyroidism: a report of an Iranian family with three consecutive pregnancies complicated by fetal goiter. Thyroid. 2005 Dec;15(12):1341-7.

7 Ribault V, Castanet M, Bertrand AM, Guibourdenche J, Vuillard E, Luton D et al; French Fetal Goiter Study Group. Experience with intraamniotic thyroxine treatment in nonimmune fetal goitrous hypothyroidism in 12 cases. J Clin Endocrinol Metab. 2009 Oct; 94(10):3731-9.

8 Ferianec V, Papcun P, Grochal F, Schenková K, Bártová M. Prenatal diagnosis and successful intrauterine treatment of severe congenital hypothyroidism associated with fetal goiter. J Obstet Gynaecol Res. 2017 Jan;43(1): 232-7.

9 Corbacioglu Esmer A, Gul A, Dagdeviren H, Turan Bakirci I, Sahin O. Intrauterine diagnosis and treatment of fetal goitrous hypothyroidism. J Obstet Gynaecol Res. 2013 Mar; 39(3):720-3.

10 Heyerdahl S, Kase BF, Lie SO. Intellectual development in children with congenital hypothyroidism in relation to recommended thyroxine treatment. J Pediatr. 1991 Jun;118(6): $850-7$.

11 Derksen-Lubsen G, Verkerk PH. Neuropsychologic development in early treated congenital hypothyroidism: analysis of literature data. Pediatr Res. 1996 Mar;39(3):561-6.

12 Kempers MJ, van der Sluijs Veer L, Nijhuisvan der Sanden MW, Kooistra L, Wiedijk BM, Faber I et al. Intellectual and motor development of young adults with congenital hypothyroidism diagnosed by neonatal screening. J Clin Endocrinol Metab. 2006 Feb;91(2): 418-24.

13 Ozguner G, Sulak O. Size and location of thyroid gland in the fetal period. Surg Radiol Anat. 2014 May;36(4):359-67.

14 Andersson M, de Benoist B, Delange F, Zupan J; WHO Secretariat. Prevention and control of iodine deficiency in pregnant and lactating women and in children less than 2-years-old: conclusions and recommendations of the Technical Consultation. Public Health Nutr. 2007 Dec;10 12A:1606-11.

15 Alexander EK, Pearce EN, Brent GA, Brown RS, Chen H, Dosiou C et al. 2017 Guidelines of the American Thyroid Association for the Diagnosis and Management of Thyroid Disease During Pregnancy and the Postpartum. Thyroid. 2017 Mar;27(3):315-89.

16 Leung AM, Avram AM, Brenner AV, Duntas LH, Ehrenkranz J, Hennessey JV et al. Potential risks of excess iodine ingestion and exposure: statement by the American thyroid association public health committee. Thyroid. 2015 Feb;25(2):145-6.

17 Trumbo P, Yates AA, Schlicker S, Poos M. Dietary reference intakes: vitamin $\mathrm{A}$, vitamin $\mathrm{K}$, arsenic, boron, chromium, copper, iodine, iron, manganese, molybdenum, nickel, sili- con, vanadium, and zinc. J Am Diet Assoc. 2001 Mar;101(3):294-301.

18 Thorpe-Beeston JG, Nicolaides KH, McGregor AM. Fetal thyroid function. Thyroid. 1992;2(3):207-17.

19 Polak M. Human fetal thyroid function. Endocr Dev. 2014;26:17-25.

20 Perelman AH, Johnson RL, Clemons RD, Finberg HJ, Clewell WH, Trujillo L. Intrauterine diagnosis and treatment of fetal goitrous hypothyroidism. J Clin Endocrinol Metab. 1990 Sep;71(3):618-21.

21 Davidson KM, Richards DS, Schatz DA, Fisher DA. Successful in utero treatment of fetal goiter and hypothyroidism. N Engl J Med. 1991 Feb;324(8):543-6.

22 Schmaltz C. Thyroid hormones in the neonate: an overview of physiology and clinical correlation. Adv Neonatal Care. 2012 Aug; 12(4):217-22.

23 Kim G, Nandi-Munshi D, Di Blasi CC. Disorders of the thyroid gland. Avery's diseases of the newborn. 10th ed. Elsevier Inc; 2018. p. 1388-402.

24 Markou K, Georgopoulos N, Kyriazopoulou $\mathrm{V}$, Vagenakis AG. Iodine-Induced hypothyroidism. Thyroid. 2001 May;11(5):501-10.

25 Wolff J, Chaikoff IL. Plasma inorganic iodide, a chemical regulator of normal thyroid function. Endocrinology. 1948 Jun;42(6):468-71.

26 Koukkou EG, Roupas ND, Markou KB. Effect of excess iodine intake on thyroid on human health. Minerva Med. 2017 Apr;108(2):13646.

27 Eng PH, Cardona GR, Fang SL, Previti M, Alex S, Carrasco $\mathrm{N}$ et al. Escape from the acute Wolff-Chaikoff effect is associated with a decrease in thyroid sodium/iodide symporter messenger ribonucleic acid and protein. Endocrinology. 1999 Aug;140(8):3404-10.

28 Wolff J, Chaikoff IL, Goldberg RC, Meier JR. The temporary nature of the inhibitory action of excess iodine on organic iodine synthesis in the normal thyroid. Endocrinology. 1949 Nov;45(5):504-13.

29 Fisher DA, Klein AH. Thyroid development and disorders of thyroid function in the newborn. N Engl J Med. 1981 Mar;304(12): 702-12.

30 Theodoropoulos T, Braverman LE, Vagenakis AG. Iodide-induced hypothyroidism: a potential hazard during perinatal life. Science. 1979 Aug;205(4405):502-3.

31 Heymann WR. Potassium iodide and the wolff-chaikoff effect: relevance for the dermatologist. J Am Acad Dermatol. 2000 Mar; 42(3):490-2.

32 Barone CM, Van Natta FC, Kourides IA, Berkowitz RL. Sonographic detection of fetal goiter, an unusual cause of hydramnios. J Ultrasound Med. 1985 Nov;4(11):625-7.

33 Mastrolia SA, Mandola A, Mazor M, Hershkovitz R, Mesner O, Beer-Weisel R et al. Antenatal diagnosis and treatment of hypothyroid fetal goiter in an euthyroid mother: a case report and review of literature. J Matern Fetal Neonatal Med. 2015;28(18):2214-20.
34 Morine M, Takeda T, Minekawa R, Sugiyama T, Wasada K, Mizutani T et al. Antenatal diagnosis and treatment of a case of fetal goitrous hypothyroidism associated with highoutput cardiac failure. Ultrasound Obstet Gynecol. 2002 May;19(5):506-9.

35 Blumenfeld YJ, Davis A, Milan K, Chueh J, Hudgins L, Barth RA et al. Conservatively managed fetal goiter: an alternative to in utero therapy. Fetal Diagn Ther. 2013;34(3):184-7.

36 Hanono A, Shah B, David R, Buterman I, Roshan D, Shah $S$ et al. Antenatal treatment of fetal goiter: a therapeutic challenge. J Matern Fetal Neonatal Med. 2009 Jan;22(1):76-80.

37 Polak M, Van Vliet G. Therapeutic approach of fetal thyroid disorders. Horm Res Paediatr. 2010;74(1):1-5.

38 Burrow GN, Fisher DA, Larsen PR. Maternal and fetal thyroid function. N Engl J Med. 1994 Oct;331(16):1072-8.

39 Calvo RM, Jauniaux E, Gulbis B, Asunción M, Gervy C, Contempré B et al. Fetal tissues are exposed to biologically relevant free thyroxine concentrations during early phases of development. J Clin Endocrinol Metab. 2002 Apr;87(4):1768-77.

40 Overcash RT, Marc-Aurele KL, Hull AD, Ramos GA. Maternal Iodine Exposure: A Case of Fetal Goiter and Neonatal Hearing Loss. Pediatrics. 2016 Apr;137(4):137.

41 Debruyne F, Vanderschueren-Lodeweyckx M, Bastijns P. Hearing in congenital hypothyroidism. Audiology. 1983;22(4):404-9.

42 Lichtenberger-Geslin L, Dos Santos S, Hassani Y, Ecosse E, Van Den Abbeele T, Léger J. Factors associated with hearing impairment in patients with congenital hypothyroidism treated since the neonatal period: a national population-based study. J Clin Endocrinol Metab. 2013 Sep;98(9):3644-52.

43 Bruno R, Aversa T, Catena M, Valenzise M, Lombardo F, De Luca F et al. Even in the era of congenital hypothyroidism screening mild and subclinical sensorineural hearing loss remains a relatively common complication of severe congenital hypothyroidism. Hear Res. 2015 Sep;327:43-7.

44 Fisher DA, Brown RS. The maturation of thyroid function in the perinatal period and during childhood. In: Braverman LE, Cooper DS, editors. Werner \& Ingbar's The Thyroid: A Fundamental and Clinical Text. 10th ed. Philadelphia: Lippincott Williams \& Wilkins; 2013. p. 775-87.

45 Lahoti A, Frank GR. Laboratory thyroid function testing: do abnormalities always mean pathology? Clin Pediatr (Phila). 2013 Apr; 52(4):287-96.

46 Abuid J, Stinson DA, Larsen PR. Serum triiodothyronine and thyroxine in the neonate and the acute increases in these hormones following delivery. J Clin Invest. 1973 May; 52(5):1195-9.

47 Erenberg A, Phelps DL, Lam R, Fisher DA. Total and free thyroid hormone concentrations in the neonatal period. Pediatrics. 1974 Feb;53(2):211-6. 